\title{
Serum testosterone does not affect bone mineral density in postmenopausal women
}

\author{
Dilek Arpaci', Fatma Saglam², Fatma Neslihan Cuhaci², \\ Didem Ozdemir², Reyhan Ersoy² Bekir Cakir ${ }^{2}$
}

${ }^{1}$ Division of Endocrinology and Metabolism, Sakarya Training and Research Hospital, Sakarya, Turkey 2 Division of Endocrinology and Metabolism, Yildirim Beyazit University, Ataturk Training and Research Hospital, Ankara, Turkey

Correspondence to: Dilek Arpaci

Division of Endocrinology and Metabolism, Department of Internal Medicine, Ataturk Training and Research Hospital,

Ankara, Turkey

drarpaci@gmail.com

Received on Sept/19/2014

Accepted on Feb/9/2015

DOI: 10.1590/2359-3997000000085

\begin{abstract}
Objective:The purpose of the present study was to investigate the correlation between serum testosterone levels and bone mineral density (BMD) in postmenopausal women. Materials and methods: The study group was made up of postmenopausal women admitted to our tertiary center. Serum calcium, phosphorus, albumin, parathyroid hormone (PTH), thyrotropin (TSH), 25-OH vitamin D, and total testosterone concentrations were measured. Subjects were categorized into three groups regarding bone mineral density (BMD) values: normal $(n=22)$, osteopenia $(n=21)$, and osteoporosis $(n=21)$. Subjects were also categorized into three groups according to serum testosterone levels: low testosterone $(n=10)$, normal testosterone $(n=42)$, and high testosterone $(n=12)$. Results: No significant difference was found for serum testosterone, TSH, calcium, phosphorus, albumin, PTH, and 25-hydroxyvitamin D levels among patients with normal BMD, osteopenia, and osteoporosis ( $p$ $>0.05$ ). Lumbar spine, total femur, femoral neck, trochanteric, intertrochanteric, and Ward's triangle BMD values were similar for the different testosterone levels $(p>0.05)$. Conclusion: There was no correlation between serum testosterone levels and patient age, body-mass index, or any measured BMD values. Given the findings in our study, which failed to demonstrate a statistically significant relationship between testosterone and BMD, adjustment of other risk factors for osteoporosis might have a more distinctive effect in this setting. Arch Endocrinol Metab. 2015;59(4):292-6
\end{abstract}

Keywords

Osteoporosis; testosterone; bone mineral density; postmenopausal women.

\section{INTRODUCTION}

$\mathrm{O}$ steoporosis is one of the most common skeletal diseases associated with susceptibility to fractures with minimal or no trauma, due to mechanical weakness and reduced bone mineral density (BMD) (1). The growth in the incidence of osteoporosis is attributed to the increase in elderly population. Accordingly, osteoporosis-related fractures have become a worldwide health problem. BMD is the current reference standard for the diagnosis of osteoporosis (2). BMD mainly depends on peak bone mass achieved during childhood, the rate of bone loss during menopause, and aging following menopause in postmenopausal women (3).

Estrogen deficiency is a well-known major risk factors for osteoporosis in women (4). However, not all women with estrogen deficiency develop osteoporosis. A recent study showed that androgens play a role in bone mass formation (5). In young women, androgen excess was shown to prevent the detrimental effects of estrogen deficiency (6). The most active androgen in women, testosterone, is a major source of estradiol in older women. According to the studies cited above and despite the possible role of androgens in the prevention of osteoporosis in premenopausal women, this issue has not been accurately clarified yet in postmenopausal women.

The aim of this study was to evaluate the effect of serum testosterone levels on BMD in postmenopausal women.

\section{MATERIALS AND METHODS}

\section{Study design}

This cross-sectional study was approved by the our Institution Review Board. Written informed consent was obtained from all subjects. Postmenopausal women admitted to the Division of Endocrinology and Metabolism of our tertiary center between April 2010 and February 2012 constituted the study group. Postmenopausal status was defined as no menses over 12 months, and FSH levels $>30 \mathrm{ng} / \mathrm{mL}$. None of the 
study participants received any kind of medication for osteoporosis, hormone replacement therapy, or steroids.

Patients with diseases that could affect serum androgen levels (e.g., diabetes mellitus, thyroid disease, adrenal insufficiency, hypogonadism, pituitary adenoma) or bone metabolism (e.g. metabolic bone disease, Paget's disease, primary or tertiary hyperparathyroidism, renal osteodystrophy, rheumatologic diseases, and malignancies), current smoking, alcoholics were excluded from the study.

\section{Outcome parameters}

History and demographic data (age, menopause age, height, weight and body-mass index) were collected from all the patients; they were also submitted to physical examination in outpatient clinics. Body-mass index (BMI) was obtained by division of weight to their height squared. Blood samples were collected after 8-12 hour overnight fastening, and serum calcium (corrected according to serum albumin levels), phosphorus, albumin, parathyroid hormone (PTH), thyroid stimulating hormone (TSH), 25-OH vitamin D and total testosterone concentrations were also measured.

The ADVIA Centaur Testosterone assay, which is a competitive immunoassay using direct chemiluminescence in Advia Centaur XP system, was used to measure serum testosterone level.

Measurement of BMD was made in the right femur and lumbar vertebra (Ll-L4) using dual X-ray energy absorptiometry (DEXA) (Hologic QDR2000 version $\left.5.4 ; \mathrm{g} / \mathrm{cm}^{2}\right)$. BMD values of the participants were categorized into three groups, according to World Health Organization: normal (T scores of $>-1.0)(\mathrm{n}=22)$, osteopenia (T score -1.0 to -2.5$)(\mathrm{n}=2 \mathrm{l})$, and osteoporosis (T scores of -2.50 or lower $(n=21)$. Participants were further categorized three groups considering their serum testosterone levels: low testosterone $(<14 \mathrm{ng} /$ dL) $(\mathrm{n}=10)$, normal testosterone $(14-76 \mathrm{ng} / \mathrm{dL})$ $(\mathrm{n}=42)$, and high testosterone $(>76 \mathrm{ng} / \mathrm{dL})(\mathrm{n}=12)$.

\section{Statistical analysis}

Data were analysed by the Statistical Package for Social Sciences 16.0 for Windows (SPSS Inc., Chicago, IL). Parametric tests were applied to data showing normal distribution, and non-parametric tests were applied to data of non-normal distribution. Pearson's $r$ was used to calculate correlation coefficients. Data were ex- pressed as mean \pm SD or medians (interquartile range), as appropriate. All differences associated with a probability of 0.05 or less were considered to be statistically significant.

\section{RESULTS}

A total of 64 postmenopausal women met the inclusion criteria for the study. Of the 64 patients whose charts were reviewed, mean age was $57.8 \pm 8.9$ (ranging from 45 to 85 ) years; mean menopause age was $45.4 \pm 5.4$ (ranging from 40 to 66 years; mean age of menopause in the country is 46) years; mean BMI was $29.2 \pm 4.9$ (ranging from 19 to 42.2 ) $\mathrm{kg} / \mathrm{m}^{2}$; mean total serum testosterone was $34.3 \pm 18.1 \mathrm{ng} / \mathrm{dL}$; and mean BMD values were $0.84 \pm 0.13 \mathrm{~g} / \mathrm{cm}^{2}$ for the lumbar spine, and $0.73 \pm 0.11 \mathrm{~g} / \mathrm{cm}^{2}$ for the femoral neck.

Demographic parameters and laboratory results of groups according to measured BMD values are shown in table 1 . With respect to demographic parameters, such as age $(\mathrm{p}=0.058)$, menopausal age $(\mathrm{p}=0.131)$, and BMI $(\mathrm{p}=0.450)$, no significant differences were observed for any of the three groups. Similarly, no significant difference was found for serum testosterone $(\mathrm{p}$ $=0.712)($ Figure 1$)$, TSH $(\mathrm{p}=0.126)$, calcium $(\mathrm{p}=$ $0.984)$, phosphorus $(\mathrm{p}=0.684)$, albumin $(\mathrm{p}=0.933)$, PTH $(\mathrm{p}=0.045)$ and 25-hydroxyvitamin $\mathrm{D}(\mathrm{p}=$ 0.986) levels for the three groups. However, a slight significant difference was found in serum PTH levels between groups $(\mathrm{p}=0.045)$.

BMI and measured BMD values in groups categorized according to testosterone levels are shown in table 2 . No significant difference was found for lumbar spine $(p=0.671)($ Figure 2$)$, total femur $(p=0.961)$, femoral neck $(\mathrm{p}=0.34 \mathrm{l})$, trochanteric $(\mathrm{p}=0.601)$, intertrochanteric $(\mathrm{p}=0.891)$, and Ward's triangle $(\mathrm{p}=$ $0.991)$ BMD values for the three groups.

Correlation analysis revealed absence of correlation between serum testosterone levels and patients age, BMI, or any measured BMD values (Table 3 ).

\section{DISCUSSION}

The purpose of the present study was to evaluate the possible effects of andogens on BMD in postmenopausal women. We showed that serum testosterone did not effect on BMD. In empirical studies, the anabolic effects of androgens on BMD has been 
Table 1. Demographic parameters and biochemical laboratory results of the groups according to bone mineral density values

\begin{tabular}{|c|c|c|c|c|}
\hline & $\begin{array}{l}\text { Normal bone density } \\
\quad(\mathrm{n}=22)\end{array}$ & $\begin{array}{l}\text { Osteopenia } \\
(\mathrm{n}=21)\end{array}$ & $\begin{array}{l}\text { Osteoporosis } \\
(\mathrm{n}=21)\end{array}$ & p Value \\
\hline Age (years) & $54 \pm 6.3$ & $56 \pm 7.9$ & $58 \pm 1.0$ & 0.058 \\
\hline Menopausal age (years) & $46 \pm 4.0$ & $44 \pm 5.4$ & $43 \pm 6.6$ & 0.131 \\
\hline $\mathrm{BMI}\left(\mathrm{kg} / \mathrm{m}^{2}\right)$ & $30.5 \pm 5.1$ & $28 \pm 5.3$ & $27.6 \pm 4.3$ & 0.450 \\
\hline Testosterone (ng/dL) (14-76) & $38.6 \pm 20.2$ & $27.1 \pm 14.7$ & $28.6 \pm 19.2$ & 0.712 \\
\hline TSH (mlU/mL) (0.35-4.94) & $2.29 \pm 2.08$ & $2.20 \pm 1.95$ & $1.54 \pm 3.0$ & 0.126 \\
\hline Calcium $_{\text {corrected }}(\mathrm{mg} / \mathrm{dL})(8.5-10.5)$ & $9.45 \pm 0.56$ & $9.40 \pm 0.42$ & $9.40 \pm 0.57$ & 0.984 \\
\hline Phosphorus (mg/dL) (2.3-4.7) & $3.7 \pm 0.79$ & $3.6 \pm 0.59$ & $3.5 \pm 0.48$ & 0.684 \\
\hline Albumin (g/dL) (3.2-5.0) & $4.4 \pm 0.31$ & $4.3 \pm 0.40$ & $3.5 \pm 0.48$ & 0.933 \\
\hline PTH (pg/mL) (11-67) & $55.1 \pm 2.98$ & $60 \pm 3.5$ & $43.6 \pm 1.37$ & 0.045 \\
\hline 25-hydroxyvitamin D (ng/mL) (25-80) & $21.5 \pm 16.3$ & $24.8 \pm 13.8$ & $23.7 \pm 14.2$ & 0.986 \\
\hline
\end{tabular}

BMl: body mass index; TSH: thyroid stimulating hormone; PTH: parathyroid hormone.

Table 2. Body mass index and bone mineral density values in groups categorized according to testosterone levels

\begin{tabular}{|c|c|c|c|c|}
\hline & $\begin{array}{l}\text { Low testosterone } \\
\qquad(\mathrm{n}=10)\end{array}$ & $\begin{array}{l}\text { Normal testosterone } \\
\qquad(\mathrm{n}=\mathbf{4 2})\end{array}$ & $\begin{array}{l}\text { High testosterone } \\
\qquad(\mathrm{n}=12)\end{array}$ & p Value \\
\hline $\mathrm{BMI}\left(\mathrm{kg} / \mathrm{m}^{2}\right)$ & $29.6 \pm 4.0$ & $29.1 \pm 5.1$ & $31.2 \pm 1.76$ & 0.641 \\
\hline Lumbar spine (L1-L4) BMD (g/cm²) & $0.82 \pm 0.13$ & $0.84 \pm 0.13$ & $0.78 \pm 0.19$ & 0.671 \\
\hline Total femur BMD (g/cm²) & $0.80 \pm 0.10$ & $0.81 \pm 0.13$ & $0.88 \pm 0.23$ & 0.961 \\
\hline Femoral neck BMD $\left(\mathrm{g} / \mathrm{cm}^{2}\right)$ & $0.73 \pm 0.13$ & $0.73 \pm 0.11$ & $0.86 \pm 0.14$ & 0.341 \\
\hline Trochanteric BMD (g/cm²) & $0.54 \pm 0.06$ & $0.58 \pm 0.13$ & $0.57 \pm 0.16$ & 0.601 \\
\hline Intertrochanteric BMD (g/cm²) & $0.91 \pm 0.13$ & $0.92 \pm 0.14$ & $1.00 \pm 0.23$ & 0.891 \\
\hline Ward's triangle BMD (g/cm²) & $0.57 \pm 0.15$ & $0.56 \pm 0.14$ & $0.57 \pm 0.15$ & 0.991 \\
\hline Body weight & $74.6 \pm 11.0$ & $71.7 \pm 13.8$ & $73.3 \pm 14.0$ & 0.364 \\
\hline Age & $58.6 \pm 6.4$ & $57.4 \pm 9.2$ & $60 \pm 10.3$ & 0.665 \\
\hline Height & $158 \pm 4.8$ & $156 \pm 6.0$ & $159 \pm 6.3$ & 0.494 \\
\hline
\end{tabular}

BMI: body mass index; BMD: bone mineral density.

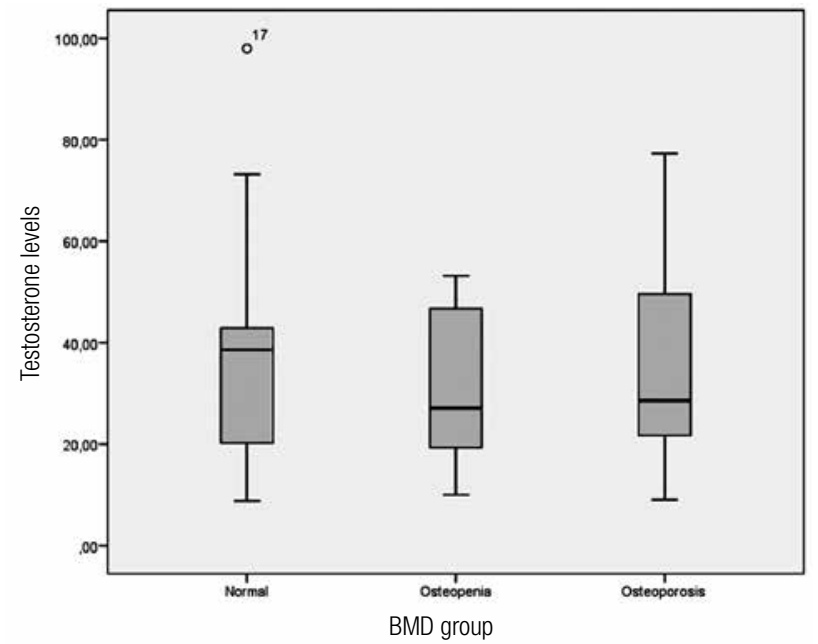

Figure 1. Testosterone levels in the BMD groups.

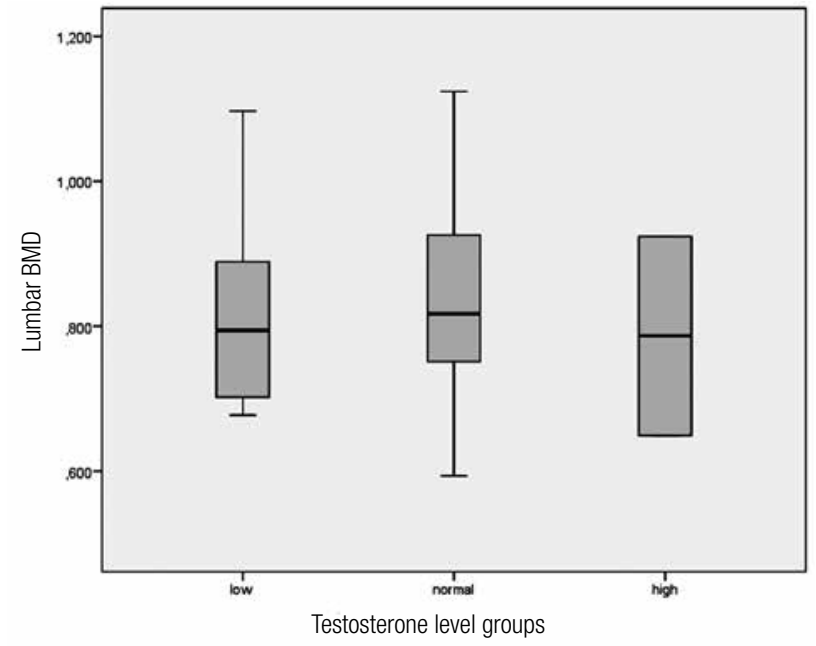

Figure 2. Lumbar BMD by testosterone level group. 
Table 3. Correlation between testosterone levels and age, body mass index, and bone mineral density values

\begin{tabular}{lcc}
\hline Variables & $\begin{array}{c}\text { Correlation } \\
\text { coefficient }\end{array}$ & p Value \\
\hline Age (years) & -0.109 & 0.391 \\
$\mathrm{BMI}\left(\mathrm{kg} / \mathrm{m}^{2}\right)$ & 0.066 & 0.607 \\
Lumbar spine $(\mathrm{L} 1-\mathrm{L} 4) \mathrm{BMD}\left(\mathrm{g} / \mathrm{cm}^{2}\right)$ & 0.043 & 0.739 \\
Total femur BMD $\left(\mathrm{g} / \mathrm{cm}^{2}\right)$ & 0.135 & 0.288 \\
Femoral neck BMD $\left(\mathrm{g} / \mathrm{cm}^{2}\right)$ & 0.197 & 0.119 \\
Trochanteric BMD $\left(\mathrm{g} / \mathrm{cm}^{2}\right)$ & 0.099 & 0.436 \\
Intertrochanteric BMD $\left(\mathrm{g} / \mathrm{cm}^{2}\right)$ & 0.122 & 0.338 \\
Ward's triangle BMD $\left(\mathrm{g} / \mathrm{cm}^{2}\right)$ & 0.148 & 0.244 \\
\hline
\end{tabular}

BMI: body mass index; BMD: bone mineral density.

stated to be directly or indirectly dependent of estrogen levels (7).

Previous reports showed that high androgen levels are associated with increased BMD in premenopause $(5,8)$. In postmenopausal women with osteoporosis and fractures, both estrogens and androgens are lower, and estradiol and androgen therapy raised their BMD (9-11). In contrast with premenopausal women, testosterone levels are not predictors of BMD in postmenopausal woman (12).

A positive correlation with testosterone concentrations and increase in BMD was confirmed by $\mathrm{Wu}$ and cols. (13). In contrast with the studies mentioned above, no association between the levels of endogen testosterone in each study group (normal, osteopenia, osteoporosis) and BMDs of any site of the body (lumbar or femoral) was found in the present study. Furthermore, there was no relationship between testosterone and BMI.

The effect of endogenous testosterone on BMD is still controversial. Several studies found no difference in serum testosterone levels between osteoporotic and non-osteoporotic postmenopausal women, supporting the findings of the present study (14-17). In other studies, no difference was found in serum testosterone levels in groups with or without fractures (18-20), testosterone did not protect bone mass (21) and not reduce fracture risk (22).

Akatsu found no association between serum testosterone and age. Age is negatively correlated with serum testosterone, androstenedione, and dehydroepiandrosterone (DHEA) levels in premenopausal and postmenopausal women (23). This is also in agreement with our findings. Navarro and cols. showed that serum estradiol levels decrease with aging; however, serum testosterone levels do not (24). As mentioned above, the mean age of menopause in our country is compatible with that of Indian women, but it seems to be somewhat different in the western population (25).

Several studies have assessed serum parathormone levels in osteoporosis and a slightly decrease was found in serum parathormone in the osteoporosis group compared with the non-osteoporotic group $(14,26)$. In our study, we found a statistically reduction in parathormone levels in osteoporosis group.

The limitations of our study are the relatively small size, being carried out in a single center, the fact that some factors that may affect the conclusions are still not completely clear, and the fact that the prevalence of bone fractures in our subjects according to the testosterone levels was not determined. Measurement of serum testosterone levels by automated methods is currently unsatisfactory. Finally, these limitations should be taken in consideration before our results are generalized.

The studies mentioned above tried to prove the importance of androgens in postmenopausal women with relative estrogen deficiency. Nevertheless, the relationship between BMD and androgens is still controversial in pre-perimenopausal periods. Therefore, further trials are necessary. The results of the presented study, taken together with similar trials that failed to demonstrate statistically significant differences between testosterone and BMD, make it possible to emphasize that adjustment of other risk factors for osteoporosis might have a more significant effect in this setting.

Disclosure: no potential conflict of interest relevant to this article was reported.

\section{REFERENCES}

1. Brown JP, Albert C, Nassar BA, Adachi JD, Cole D, Davison KS, et al. Bone turnover markers in the management of postmenopausal osteoporosis. Clin Biochem. 2009;42:929-42.

2. Kanis JA, McCloskey EV, Johansson H, Oden A, Melton LJ 3rd, Khaltaev N. A reference standard for the description of osteoporosis. Bone. 2008;42:467-75.

3. Kanis JA. Diagnosis of osteoporosis and assessment of fracture risk. Lancet. 2002;359:1929-36.

4. Johansson C, Mellstrom D, Milsom I. Reproductive factors as predictors of bone density and fractures in women at the age of 70 . Maturitas. 1993;17:39-50.

5. Adami S, Zamberlan N, Castello R, Tosi F, Gatti D, Moghetti P. Effect of hyperandrogenism and menstrual cycle abnormalities on bone mass and bone turnover in young women. Clin Endocrinol (Oxf). 1998;48:169-73. 
6. RobinsonTL, Snow-Harrer C, Taaffe DR, Gillis D, Shaw I, Marcus R. Gymnasts exhibit higher bone mass than runners despite similar prevalence of amenorrhea and oligomenorrhea. $\mathrm{J}$ Bone Miner Res. 1995;10:26-35.

7. Kasperk $\mathrm{CH}$, Wakley GK, Hierl T, Ziegler R. Gonadal and adrenal androgens are potent regulators of human bone cell metabolism in vitro. J Bone Miner Res. 1997;12:464-71.

8. Douchi T, Oki T, Yamasaki H, Kuwahata R, Nakae M, Nagata Y. Relationship of androgens to muscle size and bone mineral density in women with polycystic ovary syndrome. Obstet Gynecol. 2001;98:445-9.

9. Miller KK, Biller BM, Hier J, Arena E, Klibanski A. Androgens and bone density in women with hypopituitarism. J Clin Endocrinol Metab. 2002;87:2770-6.

10. Longcope C, Baker RS, Hui SL, Johnston Jr CC. Androgen and estrogen dynamics in women with vertebral crush. Maturitas, 1984;6:309-18.

11. Savvas M, Studd JW, Norman S, Leather AT, Garnett TJ, Fogelman I. Increase in bone mass after one year of percutaneous oestradiol and testosterone implants in post-menopausal women who have previously received long-term oral oestrogens. $\mathrm{Br} \mathrm{J}$ Obstet Gynaecol. 1992;99:757-60.

12. Khosla S, Melton III LJ, Atkinson EJ, O'Fallon WM, Klee GG, Riggs BL. Relationship of serum sex steroid levels and bone turnover markers with bone mineral density in men and women: a key role for bioavailable estrogen. J Clin Endocrinol Metab. 1998;83: 266-74.

13. Wu F, Ames R, Clearwater J, Evans MC, Gamble G, Reid IR. Prospective 10-year study of the determinants of bone density and bone loss in normal postmenopausal women, including the effect of hormone replacement therapy. Clin Endocrinol (Oxf). 2002;56:703-11.

14. Davidson BJ, Riggs BL, Wahner HW, Judd HL. Endogenous cortisol and sex steroids in patinets with osteoporotic spinal fractures. Obstet Gynecol. 1983:61;275-8.

15. Riggs BL, Khosla S, Atkinson EJ, Dunstan CR, Melton LJ 3rd. Evidence that type I osteoporosis results from enhanced responsiveness of bone to estrogen deficiency. Osteoporos Int. 2003;14:728-33.
16. Kalyani RR, Franco M, Dobs AS, Ouyang P, Vaidya D, Bertoni A, et al. The association of endogenous sex hormones, adiposity, and insulin resistance with incident diabetes in postmenopausal women. J Clin Endocrinol Metab. 2009;94:4127-35.

17. Riggs BL, Ryan TJ, Wahner HW, Jiang N, Mattox VR. Serum concentration of estrogen, testosterone and gonadotropins in osteoporotic and non-osteoporotic postmenopausal women. J Clin Endocrinol Metab. 1973;36:1097-99.

18. Otremski I, Lev-Ran M, Salama R, Edelstein S. The metabolism of vitamin D3 in response to testosterone. Calcif Tissue Int. 1997;60:485-7.

19. Moberg L, Nilsson PM, Samsioe G, Borgfeldt C. Low androstenedione/sex hormone binding globulin ratio increases fracture risk in postmenopausal women. The Women's Health in the Lund Area study. Maturitas. 2013;75:270-5.

20. Garcia-Perez MA, Moreno-Mercer J, Tarin JJ, Cano A. Relationship between PTH, sex steroid and bone turnover marker measurements and bone density in recently postmenopausal women. Maturitas. 2003;45:67-74.

21. Guthrie JR, Lehert P, Dennerstein L, Burger HG, Ebeling PR, Wark JD. The relative effect of endogenous estradiol and androgens on menopausal bone loss: a longitudinal study. Osteoporos Int. 2004;15:881-6.

22. Garnero P, Sornay-Rendu E, Claustrat B, Delmas PD. Biochemical markers of bone turnover, endogenous hormones and the risk of fractures in postmenopausal women: the OFELY study. J Bone Miner Res. 2000;15:1526-36.

23. AkatsuT. Sex steroids, bone turnover and bone mineral density in pre-, peri-, and postmenopausal woman. Environ Health and Prev Med. 1998;3:123-9.

24. Navarro D, Acosta A, Robles E, Diaz C. Hormone profile of menopausal women in Havana. MEDICC Rev. 2012;14:13-5.

25. Mozumdar A, Agrawal PK. Prevalence, trends, and determinants of menopause in India: NFHS 1992-93 to NFHS 2005-06. Am J Hum Biol. 2015;27(3):421-5.

26. Riggs $B L$, Arnaud $C D$, Jowsey J. Parathyroid function in primary osteoporosis. J Clin Invest. 1973:52;181-4. 